\title{
Children's Citrus Activity: Citrus Counting ${ }^{1}$
}

\author{
Jamie D. Burrow and Ariel Singerman ${ }^{2}$
}

Florida is well known for its citrus industry, which is valued at over 8 billion dollars, and is one of the top citrusproducing states in the United States. Over $90 \%$ of Florida's citrus crop is processed (squeezed) for juice. Florida orange juice is shipped around the world. The most common citrus fruit grown in Florida is the Valencia orange, but grapefruit, lemons, limes, and tangerines are also grown in Florida.

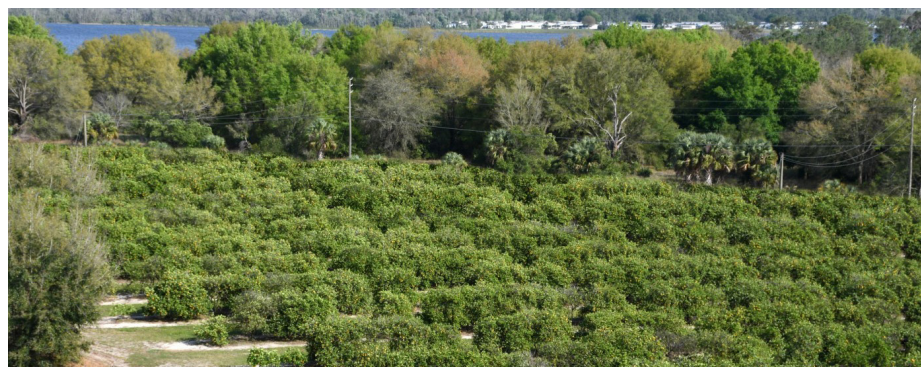

Figure 1. A University of Florida orange grove in Lake Alfred, Florida.

Directions: It takes 4 medium oranges to make an 8-ounce glass of orange juice. Circle the four matching oranges.
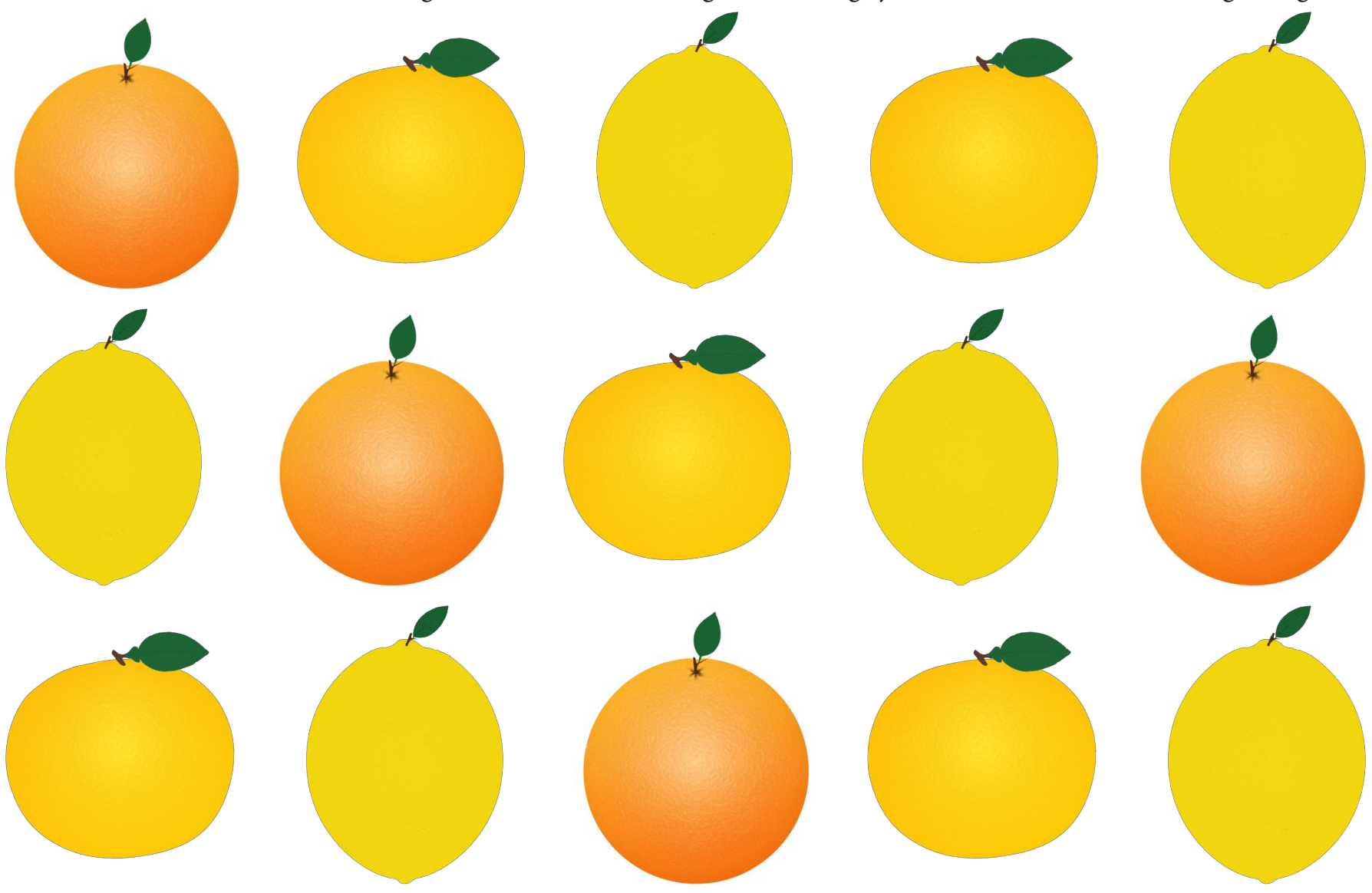

1. This document is $4 \mathrm{H} 402$, one of a series of the 4-H Youth Development Program, UF/IFAS Extension. Original publication date July 2019. Visit the EDIS website at https://edis.ifas.ufl.edu for the currently supported version of this publication.

2. Jamie D. Burrow, Extension program manager, and Ariel Singerman, assistant professor, Food and Resource Economics Department, UF/IFAS Citrus Research and Education Center, Lake Alfred, FL 33850.

The Institute of Food and Agricultural Sciences (IFAS) is an Equal Opportunity Institution authorized to provide research, educational information and other services only to individuals and institutions that function with non-discrimination with respect to race, creed, color, religion, age, disability, sex, sexual orientation, marital status, national origin, political opinions or affiliations. For more information on obtaining other UF/IFAS Extension publications, contact your county's UF/IFAS Extension office. 